\title{
What do employers think their role is in ensuring language proficiency of internationally trained pharmacists (ITPs)
}

DOI:

10.1111/ijpp.12379

\section{Document Version}

Accepted author manuscript

Link to publication record in Manchester Research Explorer

\section{Citation for published version (APA):}

Ziaei, Z., Hassell, K., \& Schafheutle, E. (2017). What do employers think their role is in ensuring language proficiency of internationally trained pharmacists (ITPs). International Journal of Pharmacy Practice, 26, 148-155. https://doi.org/10.1111/ijpp.12379

\section{Published in:}

International Journal of Pharmacy Practice

\section{Citing this paper}

Please note that where the full-text provided on Manchester Research Explorer is the Author Accepted Manuscript or Proof version this may differ from the final Published version. If citing, it is advised that you check and use the publisher's definitive version.

\section{General rights}

Copyright and moral rights for the publications made accessible in the Research Explorer are retained by the authors and/or other copyright owners and it is a condition of accessing publications that users recognise and abide by the legal requirements associated with these rights.

\section{Takedown policy}

If you believe that this document breaches copyright please refer to the University of Manchester's Takedown Procedures [http://man.ac.uk/04Y6Bo] or contact uml.scholarlycommunications@manchester.ac.uk providing relevant details, so we can investigate your claim.

\section{OPEN ACCESS}




\section{What do employers think their role is in ensuring language proficiency of internationally trained pharmacists (ITPs)}

Zainab Ziaei, $\mathrm{PhD}$,

PhD Graduate

Karen Hassell, $\mathrm{PhD}$

Professor in Social Pharmacy

Ellen I. Schafheutle, MSc, Mres, PhD, FFRPS, MRPharmS

Senior Lecturer in Law \& Professionalism in Pharmacy

Director, Centre for Pharmacy Workforce Studies

All: Centre for Pharmacy Workforce Studies, Division of Pharmacy and Optometry, School of Health Sciences, Faculty of Biology, Medicine and Health, The University of Manchester, Manchester, UK. Emails: zainabziaei@gmail.com, karen.hassell@manchester.ac.uk, ellen.schafheutle@manchester.ac.uk

Corresponding author:

Dr Zainab Ziaei. zainab.ziaei@gmail.com

\section{Key words:}

Internationally trained pharmacist; Employer; Pharmacy, Patient safety, communicative proficiency

Ethical approval for this paper was obtained from Oldham Local Research Ethics Committee

Dr. Zainab Ziaei, the author of the paper, was a PhD student at Manchester University. She designed the project, collected and analysed the data during her $\mathrm{PhD}$ research. Prof. Karen Hassell and Dr. Ellen I. Schafheutle, co-authors of the paper, supervised the project, guided with the design of the study and validated the analysis. All authors had complete access to the study data which support this publication.

DOI: $10.1111 /$ hsc. 12397

To appear in: International Journal of Pharmacy Practice

Please cite this article as: Ziaei Z, Hassell K, Schafheutle EI. What do employers think their role is in ensuring language proficiency of internationally trained pharmacists (ITPs). International Journal of Pharmacy Practice: DOI: 10.1111/ijpp.12379

This is a PDF file of the unedited manuscript accepted for publication on 3 April 2017. 


\section{ABSTRACT}

2 Objectives: Until 2016, internationally trained pharmacists (ITPs) from the European Economic

3 Area (EEA) did not need to prove sufficient language proficiency to the pharmacy regulator

4 upon registration. Pharmacists themselves have a professional responsibility to ensure they can

5 communicate and work effectively, but some responsibility also rests with employers, yet very

6 little research has explored this. The aim of this study was to explore employer views of the

7 communicative proficiency of ITPs whose first language was not English, their role as

8 employers, and potential implications for patient safety. Methods: Semi-structured, telephone

9 interviews were conducted with seven community and two hospital employers with experience

10 of employing EEA pharmacists, between May and July 2010. Verbatim interview transcripts

11 were coded and analysed in NVivo using the framework approach. Key findings: All

12 participants mentioned the importance of having processes in place to assure EEA pharmacists'

13 linguistic competency in the workplace. During recruitment, different strategies were used to

14 assure language competency. Some employers only conducted interviews while others required

15 candidates to pass English language assessments. Participants were most familiar with the

16 International English Language Testing System (IELTS), which was described as too general

17 and not unique to pharmacy. Other pharmacy specific tests such as the University of Bath

18 English Language Test and Linguarama English Assessment Test for Pharmacists were

19 alternatives. Conclusions: Currently, there is no one standard procedure in place to check the

20 communicative competency of EEA pharmacists. The findings from this study suggest that there

21 is need to establish a uniform assessment system so all the EEA pharmacists could be tested

22 justly and consistently. 


\section{Introduction}

25 During the last decade, internationally trained healthcare professionals have been recruited to

26 public and private healthcare providers to alleviate manpower shortages. ${ }^{1-8}$ They are either

27 'actively recruited,' where employers or agencies actively seek internationally trained healthcare

28 professionals to fill shortages, or they themselves drive the move, registration and work. ${ }^{8}$ In

29 pharmacy in Great Britain (GB - England, Scotland and Wales), the proportion of internationally

30 trained pharmacists (ITPs) has risen from $10.1 \%$ in 2004 to $11.8 \%$ in $2011 .^{7}$ Whilst a great deal

31 of research has been undertaken on internationally trained doctors (ITDs) and nurses (ITNs), less

32 is known about internationally trained pharmacists (ITPs). ${ }^{9-18}$ It is known that internationally

33 trained healthcare professionals, including pharmacists, face numerous challenges in their

34 adaptation process into the host heal the care system. ${ }^{10-18}$ Where English is a foreign language,

35 the literature on ITNs and ITDs has identified language and communication barriers as a root

36 cause for issues related to adaptation and integration of these healthcare professionals into the

37 workforce, with some studies raising the potential impact of communication problems on patient

38 safety and quality of care. ${ }^{19-25}$

39 Only one qualitative study undertaken in GB has explored communicative proficiency of ITPs

40 and its potential impact on patient safety. ${ }^{20}$ This study showed that, besides inadequate oral

41 proficiency in English, different dialects, use of idioms and colloquial language could cause

42 difficulties to ITPs. Limited knowledge about the cultural norms, which are closely related to

43 verbal and non-verbal communication, also caused difficulties. ${ }^{20}$

44 In GB, ITPs who join from outside the European Economic Area (EEA) need to undergo 45 language testing in the form of achieving level seven in in every category of the International 
46 English Language Testing System (IELTS) ${ }^{26,27}$ Initially designed to assess English language

47 skills for admission to programmes of academic study, the IELTS has now been adopted by a 48 number of healthcare regulatory bodies as a reliable means to test English language skills for the

49 workplace. ${ }^{28 ; 29}$ However, Austin and Galli have argued that examinations such as IELTS do not 50 sufficiently capture pharmacists' communication related deficiencies. ${ }^{30}$ These findings were

51 supported by $\mathrm{Xu}$ who believed one of the limitations of these standardised tests is their inability

52 to assess the socio-cultural dimension of language. ${ }^{31}$ To overcome these barriers, pharmacy

53 specific tests such as the University of Bath English Language Test (UBELT) and the

54 Linguarama English Assessment Test for Pharmacists have been used by some employers. ${ }^{32 ; 33}$

55 To date, the General Pharmaceutical Council (GPhC), the pharmacy regulator in GB, is currently 56 not able to test the language skills of EEA pharmacists applying for registration. ${ }^{34}$ However,

57 whilst healthcare regulators, including the GPhC, were given the power to ask for evidence of

58 English language competence, proposals have been consulted on but not yet implemented. ${ }^{35 ; 36}$

59 Nevertheless, pharmacists have, under the Standards of Conduct, Ethics and Performance a

60 professional responsibility to ensure that they - and everyone they are responsible for - have

61 "sufficient language proficiency to communicate and work effectively with colleagues." ${ }^{34}$ Some

62 onus is thus on employers to ensure that pharmacists have sufficient technical and linguistic

63 skills to perform their job safely. ${ }^{32}$

64 In 2009, the Royal Pharmaceutical Society of Great Britain (RPSGB), the previous pharmacy

65 regulator, conducted an online survey of 1500 pharmacy employers investigating issues relating

66 to English language abilities of pharmacists working in GB (response rate 11\%). Sixty-three

67 percent of respondents disclosed that language testing of EEA job applicants was not routinely

68 undertaken and $40 \%$ had experienced problems with employees' grasp of English, such as 
69 difficulties talking to patients and colleagues, problems understanding standard operating

70 procedures and difficulty with reading prescriptions..$^{32 ; 37 ; 38}$ The survey also revealed that $55 \%$ of

71 pharmacy employers were unaware of the restrictions that prohibited the regulator from testing

72 the language proficiency of EEA applicants. ${ }^{32 ; 37}$ Besides this survey, little is known about

73 employers' views and experiences of the communicative proficiency of ITPs whose first

74 language was not English, their role as employers, and potential implications for patient safety.

75 This study aimed to address this.

\section{Methods}

77 Semi-structured telephone interviews were conducted with a purposively selected sample of 78 community and hospital employers, with directors of human resources (HR), superintendent

79 pharmacists and area managers in community pharmacy and chief pharmacists in hospitals

80 identified as those holding responsibility for staff and high quality and ethical provision of

81 pharmacy services within their organisation. ${ }^{39 ; 0}$ Twenty individuals who had in the past

82 employed, or were currently employing EEA pharmacists, working in a selection of small,

83 medium and large community pharmacy chains, and university teaching/district general hospitals

84 were identified and recruited via personal networks and snowball sampling. Participants'

85 eligibility, ie if they either currently or in the past employed EEA pharmacists was further

86 confirmed when they expressed interest in study participation.

87 These twenty individuals in the NorthWest of England were contacted via email, containing an

88 invitation letter and information sheet, followed by a reminder after 10-14 days. Individuals who

89 replied were emailed a consent form, which they were asked to complete, sign and return. 
90 Considerable efforts were made to recruit a sufficiently large number of interviewees; indeed,

91 contact was made with a total of twenty individuals in eight organisations.

92 The study obtained National Research Ethics Service and University ethics approval.

93 A broad ranging interview guide was devised based on published literature..$^{30 ; 32 ; 37 ; 41-43}$

94 Interviews began by exploring how participants had started recruiting ITPs; whether

95 employers undertook language testing prior to ITPs starting work in their organisation; if they

96 provided any training for ITPs; and what barriers they faced in identifying poor

97 communication. Using examples of complaints or incidents, identified by interviewees

98 involving ITPs due to communication issues, it was discussed how employers managed poor

99 communication. Finally, participants were asked about the employers' responsibility when

100 recruiting ITPs.

101 Interviews were conducted between May and July 2010. Interviews were audio-recorded,

102 transcribed verbatim, coded and analysed in Nvivo 8 using the framework approach. ${ }^{44}$ This

103 approach allows themes and categories to be set from the beginning based on the research

104 questions and the available literature but also allows for categories and themes to emerge

105 from the data themselves. ${ }^{44}$

\section{Results}

107 Of the twenty individuals approached, nine interviews were conducted with employers in 108 community $(n=7)$ and hospital $(n=2)$. Further information on participants' profiles is presented in

109 Table 1. In the table, the first two colour-coded categories contain personnel who were broadly

110 responsible for the recruitment, placement of ITPs, course provision, induction and adaptation. 
111 All but one of these were pharmacists. The area and cluster managers in the last category were

112 those most closely involved with ITPs on a day-to-day or weekly basis and who provided on-

113 going support and guidance. Interviews lasted about between 30 and 40 minutes.

\section{Recruitment process}

115 Interviewees employed ITPs following both active and passive recruitment; however, they

116 mainly talked about active recruitment, where they took a proactive role in identifying and

117 recruiting ITPs and facilitating their registration and employment. All interviewees said that the

118 recruitment of EEA pharmacists started six to seven years prior to this study:

"Our first Spanish pharmacist was recruited six years ago when there was a short-fall in basic grade pharmacists. So a number of chief pharmacists went over to Spain and did a big recruitment event.” (E1)

122 During the interviews, employers were asked about the recruitment process and specifically if 123 language testing of the EEA pharmacists was conducted. One hospital and one community 124 employer believed no guidelines were available from the regulator concerning language 125 proficiency of EEA pharmacists at the time when they were still actively recruiting from abroad. 126 They explicitly mentioned that testing for language proficiency was not carried out uniformly:

"We did an interview with the pharmacists to look at their language...last time we went to Poland, there wasn't any guidance from the RPSGB...at that point we weren't doing any formal language testing.” (E6)

130 All the other seven employers mentioned that, in addition to interviewing the candidate, they also

131 aimed to test language proficiency by other means. One hospital employer explained that their 
132 recruitment process involved completion of an English proficiency test just before the interview

133 began:

134

"Pharmacists had to sit an English test, written and spoken... So when they came for their interview, we had a fair idea what their English was like.” (E3)

136 Most employers were familiar with IELTS as a means to testing language proficiency but three

137 shared several concerns related to it:

138

“We never used IELTS. I can't see the benefits of doing a general test...I was also a bit concerned because anecdotally we were hearing that people were being coached to pass it.” (E5)

140 Two of the community employers talked about using more tailored language tests that had to be 141 completed by EEA candidates before they could join the company:

"Pharmacists had to also pass a test. Our standardised test is the Linguarama because they tailored it around the medical profession. However, we will accept certain other tests, like IELTS. ” (E8)

147 When actively recruiting, interviewees described their direct involvement in the recruitment and

148 interviewing process. They interviewed in GB or the source EEA country. A combination of 149 qualifications and experience were usually sought and were explored in the interview. Detailed 150 technical questions relating to pharmacy practice were used to test EEA pharmacists' expertise 151 and knowledge. Some employers used 'Behaviour Interviewing'. This involved using questions 152 to explore how an applicant might deal with, or react to, a particular situation, or how they had 
153 dealt with such a situation in the past. ${ }^{45}$ Employers always emphasised that they were looking for 154 the best person for the job:

"They would be asked technical questions during the interview. For example, how they would deal with an asthmatic child who is suffering with a persistent cough?... We were looking for a range of skills.” (E8)

158 All employers interviewed believed that it is important that language skills of ITPs meet 159 professional standards before they can be employed. They all insisted that they had a rigorous process in place to ensure their competency: "Communication is very important and pharmacists have to be able to communicate. We did our best to make sure of that...after our adaptation programme our recruited pharmacists were ready to practise.” (E1)

\section{Patient safety}

165 Only one of the nine employers interviewed believed patient safety might be compromised 166 because of communication difficulty:

"The main concern is that the patient would not understand what they're (pharmacists) saying, so they could take the tablet in a different way... So there is a possibility that the patient's safety could be jeopardised." (E4)

170 This employer went on further to describe how, besides patient safety, patient loyalty and patient

171 trust could also be affected by poor communication: him, because they don't understand him, that could affect them coming back again." (E4) 
174 Although patient safety was a concern that was raised by one employer, the other eight

175 participants did not have concerns over patient safety and the quality of care EEA pharmacists

176 provided:

“We are confident that they (pharmacists) are able to communicate. We wouldn't recruit them if we didn't believe that their language is good enough, so patient safety is not compromised." (E8)

\section{Employers' responsibility towards ITPs' language skills}

180 Employers were asked who they thought should be responsible for checking the language

181 proficiency of EEA pharmacists. Almost all (eight) interviewees believed this should be the 182 employers' responsibility:

"For me, I think it's the employer's responsibility because, at the end of the day, they would be representing that particular employer." (E2)

185 Other employers explained that they had a duty of care to their customers and, as part of that 186 duty, they have to ensure the language proficiency of their EEA pharmacists:

"As the employer, we have a duty of care to our customers and our patients and part of that duty is to ensure that pharmacist know the language." (E8)

189 Only one employer believed that the regulator should have the responsibility for checking EEA

190 pharmacists' language proficiency before registering them:

"We were actually quite shocked at how easy it is to be able to register,... I think it is the regulator's responsibility to check the language proficiency as part of registration process." (E1) 
193 A hospital employer raised a general concern about EEA pharmacists who were not employed

194 but worked as locums, ${ }^{\text {a }}$ suggesting that this may be an area where the regulator needed to play a 195 role:

"EEA pharmacists could come over and start locuming straight away and no one would know how good their English is. If the Society could test the language then it wouldn't be such a worry for employers." (E1)

\section{Adaptation}

200 All seven community pharmacy employers stressed that they provided adaptation programmes to 201 actively recruited EEA pharmacists to prepare them for work in GB. The adaptation programmes 202 varied in length but usually lasted between four to twelve weeks: adaptation period.”(E2)

\section{Discussion}

206 This study presents novel qualitative insights from interviews with employers of ITPs in 207 community and hospital settings in GB. Those interviewed were mainly talking about their 208 experience of active recruitment of ITPs, which involved interviews and limited language

209 testing. Not all employers were aware that, at the time, the regulator had no power to assess

210 English language competence of EEA pharmacists, yet most saw the employer as holding some 211 responsibility. Only one interviewee talked about a potential impact on patient safety. However,

\footnotetext{
a a locum pharmacist is a pharmacist who temporality fulfills the duties of the permanent pharmacists. ${ }^{46}$
} 
212 interviewees acknowledged that language proficiency may be more of an issue for pharmacists

213 who joined the register without employer involvement and recruitment.

214 The findings stem from a qualitative study involving just nine interviews. Recruitment of

215 employers of ITPs proved difficult, partly due to their general busyness, but this topic may also

216 have been considered sensitive by employers, leading to reluctance to be open about problems

217 with ITPs they appointed or their recruitment processes. Responses from the seven community

218 pharmacy employers were relatively homogenous, so it is likely that data saturation was reached

219 with this group; data saturation may not have been achieved with hospital employers. ${ }^{47}$

220 Nevertheless, novel, insightful themes were captured. Because interviewees were working, or

221 had worked, directly with ITPs, this gave them good awareness of ITPs' abilities, including

222 communication, and their standard of care. Securing interviews with pharmacist and non-

223 pharmacist employers, who had a range of responsibilities in terms of recruiting, training,

224 supporting and managing ITPs, was valuable. However, interviewees may not have talked about

225 all problems they had experienced with their recruited ITPs, as this may have been perceived as

226 showing their organisation in a poor light. These findings should be tested in a larger survey with

227 employers in community and hospital pharmacy. Furthermore, experience with active

228 recruitment dominated in this study, yet those entering the register independently, outside a

229 formal recruitment and management system, may pose additional challenges. ${ }^{48-50}$

230 Despite recognising English as a challenge, all but one employer believed that the delivery of

231 safe and ethical care was not compromised when their EEA recruits first entered GB practice.

232 They believed that high standards were maintained by their rigorous recruitment and adaptation

233 programme. All interviewees mentioned the significance of having some process in place to

234 assure language proficiency of EEA pharmacists in the workplace; however, these processes 
235 varied in type and rigorousness. Two employers only conducted interviews to assess proficiency,

236 while others tested the language proficiency of EEA candidates prior to interviews using

237 established English language assessment tools. Interviewees were most familiar with the IELTS,

238 but some shared concerns in relation to this assessment, in particular that it could be passed

239 despite communication problems. ${ }^{51}$ Whilst a number of healthcare regulators use IELTS as a

240 means to English language testing for the workplace, IELTS has been described as being too

241 general and not occupation specific, and passing it was not a good indicator of fluency in the

242 workplace. ${ }^{26 ; 28-30 ; 52-54}$ While IELTS may be appropriate to measure language proficiency for

243 entry to academic studies, it may not be appropriate for testing broader skills, such as those

244 required for healthcare professionals, ${ }^{55}$ who may require testing on occupation specific

245 components. ${ }^{56}$ Indeed, some community employers used the UBELT and the Linguarama

246 English Assessment Test. ${ }^{32 ; 33}$ These are pharmacy-specific language tests, with tasks designed

247 based on an analysis of language communication needs in GB community pharmacy. ${ }^{57 ; 58}$ Further

248 study will need to establish the most appropriate tests suitable for professional pharmacy

249 practice.

250 According to the GPhC standards of conduct, ethics and performance, pharmacists have a duty to

251 ensure that they, and those employed by them, have sufficient language competence to

252 communicate and work effectively. ${ }^{34}$ Nevertheless, employers also have responsibility to ensure

253 that staff have sufficient technical and linguistic skills to perform their job safely. Interviewees

254 acknowledged their responsibility to ensuring patient safety, and that checking the language

255 proficiency of their EEA recruits was part of that. In contrast, the RPSGB's survey found that

$25663 \%$ of employers did not routinely undertake language testing of European job applicants,

257 despite more than a third having experienced problems with employees' grasp of English. ${ }^{32 ; 37}$ 
258 Further concerns were raised over EEA pharmacists who may register but not enter employment,

259 such as locums, and thus not fall under any management structures. Locum pharmacists are

260 usually self-employed, with no organisation having responsibility for identifying and managing,

261 or sharing information on, their performance concerns, with potential patient safety

262 implications. ${ }^{59-63}$

263 Individual pharmacy companies and the regulatory body can use the findings of this work to

264 inform their approaches to support the recruitment and the adaptation of ITPs in GB. Employers

265 in this study stated that their fundamental responsibility was to ensure patient safety and check

266 the language proficiency of their new EEA recruits, and providing adaption programmes was a

267 step through which this was achieved. Further research is needed to link language proficiency to

268 clinical outcomes and patient safety, to establish if communication challenges pose a real risk to

269 patient safety. Furthermore, future study should test the effectiveness of the recently published

270 GPhC guidance on language testing. The findings from this and future studies could then inform

271 the regulator's implementation to their approach to language testing.

272

273 Declarations

274 Conflict of interest

275 The author(s) declare(s) that they have no conflicts of interest to disclose. 


\section{Reference list}

1. Aluttis $\mathrm{C}$ et al. The workforce for health in a globalized context-global shortages and international migration. Glob Health Action. 2014;7. Available at: https://www.ncbi.nlm.nih.gov/pmc/articles/PMC3926986/ Accessed 30.03.117

2. Bradby H. International medical migration: a critical conceptual review of the global movements of doctors and nurses. Health (London). 2014;18(6):580-96

3. Buchan J. International recruitment of nurses: Policy and practice in the United Kingdom. Health Serv Res. 2007;42:1321-1335.

4. George JT et al. Non-European Union doctors in the National Health Service: why, when and how do they come to the United Kingdom of Great Britain and Northern Ireland? Hum Resour Health. 2007;5:6-16.

5. Schafheutle E, Hassell K. Internationally trained pharmacists in Great Britain: what do registration data tell us about their recruitment? Hum Resour Health. 2009;7(1):51-61.

6. Goldacre MJ et al. Country of training and ethnic origin of UK doctors: database and survey studies. Brit Med J. 2004; 329(7466):597-600.

7. Hassell K. CPWS Briefing Paper: GPhC Register Analysis 2011. London, UK: General Pharmaceutical Council, 2012.

8. Mills E et al. Should active recruitment of health workers from sub-Saharan Africa be viewed as a crime? Lancet. 2008;371(9613):685-688.

9. Pung LX, Goh YS. Challenges faced by international nurses when migrating: an integrative literature review. Int Nurs Rev. 2017;64(1):146-65.

10. Walani SR. Global migration of internationally educated nurses: Experiences of employment discrimination. International Journal of Africa Nursing Studies 2015;3:6570.

11. Li $\mathrm{H}$ et al. The benefits and caveats of international nurse migration. International Journal of Nursing Sciences. 2014;1(3):314-7.

12. Nichols J, Campbell J. The experiences of internationally recruited nurses in the UK (1995-2007): An integrative review. J Clin Nurs. 2010;19(19-20):2814-23.

13. Jenkins BL, Huntington A. A missing piece of the workforce puzzle. The experiences of internationally qualified nurses in New Zealand: A literature review. Contemporary Nurse. 2015;51(2-3):220-31.

14. Allan H, Larsen JA. "We need respect": experiences of internationally recruited nurses in the UK. London, UK: Royal College of Nursing, 2003.

15. Smith DJ. Overseas doctors in the National Health Service. Policy Studies. 1982; 3(1):12-20.

16. Winkelmann-Gleed A, Seeley J. Strangers in a British world? Integration of international nurses. Br J Nurs. 2005;14(18):954-961. 
17. Smith $\mathrm{P}$ et al. Valuing and Recognising the Talents of Diverse Healthcare Workforce. London, UK: Royal College of Nursing, 2006.

18. Kangasniemi $\mathrm{M}$ et al. Is the medical brain drain beneficial? Evidence from overseas doctors in the UK. Soc Sci Med. 2007; 65(5):915-923.

19. Austin Z. Geographical migration, psychological adjustment, and re-formation of professional identity: the double-culture shock experience of international pharmacy graduates in Ontario (Canada). Globalisation, Societies and Education. 2007; 5(2):239255.

20. Ziaei Z et al. Internationally trained pharmacists' perception of their communication proficiency and their views on the impact on patient safety. Res Social Adm Pharm. 2015; 11(3):428-441.

21. Davis CR, Nichols BL. Foreign-Educated Nurses and the Changing U.S. Nursing Workforce. Nurs Adm Q. 2002; 26(2):43-51.

22. Xu Y. Strangers in strange lands: A meta-synthesis of lived experiences of immigrant Asian nurses working in Western countries. Adv Nur Sci. 2007; 30(3):246-65.

23. Xu Y et al. Adaptation and transformation through (un)learning: lived experiences of immigrant Chinese nurses in US healthcare environment. Adv Nurs Sci. 2008; 31(2):E33E47.

24. Lum L et al. Internationally educated nurses' reflections on nursing communication in Canada. Int Nurs Rev. 2016;63(3):344-51.

25. Lum L et al. Challenges in oral communication for internationally educated nurses. $J$ Transcult Nurs. 2015;26(1):83-91.

26. Overseas Pharmacists Assessment Program. General Pharmaceutical Council. Available at:http://www.pharmacyregulation.org/sites/default/files/International\%20Information $\% 2$ 0Pack\%20Mar\%202012.pdf. Accessed 30.03.117

27. Recognition as an EEA qualified pharmacist. General Pharmaceutical Council. Available at:http://www.pharmacyregulation.org/sites/default/files/EEA\%20Standard\%20Informati on\%20pack\%20February\%202012.pdf. Accessed 14.07.15

28. Registering as a nurse or midwife in the United Kingdom. For applicants from countries outside the European Economic Area. Nursing and Midwifery Council. Available at: http://ww2.anglia.ac.uk/ruskin/en/home/microsites/placements/overseas_nursing.Mainco ntent.0032.file.tmp/Registering\%20as\%20a\%20nurse\%20or\%20midwife $\% 20$ from $\% 20 \mathrm{ou}$ tside\%20EU\%20or\%20EEA.pdf. Accessed 14.07.15

29. Professional and Linguistic Assessments Board (PLAB). General Medical Council. Available at: http://www.gmc-uk.org/doctors/plab.asp. Accessed 14.07.15

30. Austin Z, Galli M. Assessing communicative competency of international pharmacy graduates in Ontario, Canada. J Soc Admin Pharm. 2003; 20(6):225-230.

31. Xu Y. Is transition of internationally educated nurses a regulatory issue? Policy Polit Nurs Pract. 2010; 11(1):62-70. 
32. Rivers F. Who should test the English language skills of European pharmacists? Pharm J. 2009; 283:204-205.

33. Richardson J. Lost in translation: English language tests. Chemist \& Druggist. 2008.

34. EEA qualified pharmacist. General Pharmaceutical Council. Available at: http://www.pharmacyregulation.org/registration/registering-pharmacist/eea-qualifiedpharmacists. Accessed 14.07.15

35. New language ability checks for EU trained healthcare workers. Department of Health. Available at: https://www.gov.uk/government/news/new-language-ability-checks-for-eutrained-healthcare-workers. Accessed 26.09.16 Accessed 14.07.15

36. Guidance on evidence of English language skills. General Pharmaceutical Council. Available at: https://www.pharmacyregulation.org/sites/default/files/guidance_on_evidence_of_englis h_language_skills.pdf Accessed 30.03.17

37. Pharmaceutical Journal. More than half of pharmacy employers don't check applicants' English language skills. Pharm J. 2009; 282:693.

38. Pharmaceutical Journal. EEA pharmacists' English not tested by employers. Pharm J. 2009; 283:197.

39. Pharmaceutical Journal. Boots to get rid of area pharmacy managers. Pharm J. 2010; 284:494.

40. Chief Pharmacist. Yeovil Hospital. Available at: http://www.yeovilhospital.co.uk/wpcontent/uploads/2014/01/Chief-Pharm-Recruitment-brochure.pdf. Accessed 14.07.15.

41. Richardson J. Lost in translation: English language tests. Chemist \& Druggist. 2008.

42. Pharmaceutical Journal. Overseas pharmacists should have to prove their competence in the English language, BRM decides. Pharm J. 2008; 280:731.

43. Austin Z, Dean MR. Development of a Curriculum for Foreign-trained Pharmacists Seeking Licensure in Canada. Pharm Educ. 2004; 4(3):143-151.

44. Ritchie J et al. Carrying out Qualitative Analysis. In: Ritchie J, Lewis J. Qualitative Research Practice: A Guide for Social Science Students and Researchers. London: SAGE Publications, 2003: 219-262.

45. Behavioural interview. Virginia Tech. Available at: http://www.career.vt.edu/interviewing/behavioral.html. Accessed 14.07.15.

46. Malson G. Consider a career as a locum pharmacist. Pharm J. 2014. http://www.pharmaceutical-journal.com/publications/tomorrows-pharmacist/consider-acareer-as-a-locum-pharmacist/20066536.article. Accessed 14.07.15.

47. Guest et al. How many interviews are enough? An experiment with data saturation and variability. Field Methods. 2006:18 (1): 59-82.

48. Pharmaceutical Journal. Facing the recruitment and retention crisis in pharmacy: looking abroad. Pharm J. 2001; 267(7156):45-46.

49. Wang LN. Eastern European pharmacists in the UK. Pharm J. 2007; 278(7433):7-8. 
50. Masom P. As the European Union expands, what are the implications for pharmacy? Pharm J. 2004; 272(7297):537-538.

51. Epp et al. Benchmarking the English Language Demands of the Nursing Profession across Canada. Ottawa, Canada: Centre for Canadian Language Benchmarks, 2002.

52. Pilotto L et al. Issues for clinicians training international medical graduates: a systematic review. Med J Aust. 2007; 187(4):225-228.

53. Hashmi A. Communication skills of overseas doctors and training implications for psychiatry. Psychiatric Bulletin. 2009; 33:275-275.

54. Yahes E, Dunn AK. Enculturation of foreign nurse graduates: an integrated model. $J$ Contin Educ Nurs. 1996; 27(3):120-123.

55. Merrifield G, GBM \& Associates. An impact study into the use of IELTS by professional associations and registration entities: Canada, the United Kingdom and Ireland. IELTS Research Reports. 2012; 11:1-53.

56. Merrifield G. An impact study into the use of IELTS as an entry criterion for professional associations - Australia, New Zealand and the USA. IELTS Research Reports. 2008; 8:143.

57. University of Bath taking English language testing to Romania and Poland. University of Bath. Available at: http://www.bath.ac.uk/news/2009/05/12/ubelt/. Accessed 14.07.15.

58. Linguarama English Assessment Test for Pharmacists. Linguarma. Available at: http://www.linguarama.com/courses/english-tests-for-pharmacists Accessed 14.07.15.

59. Ziaei Z et al. Work experiences of internationally trained pharmacists in Great Britain. Int Journ Pharm Prac. 2015; 23(2)131-40.

60. Jee $\mathrm{S}$ et al. An exploration of the utility of appraisals for the revalidation of pharmacy professionals in community pharmacy in Great Britain. Res Social Adm Pharm. 2013; 9: $155-165$

61. Schafheutle EI et al. Ensuring continuing fitness to practise in the pharmacy workforce: Understanding the challenges of revalidation. Res Social Adm Pharm. 2013; 9: 199-214

62. Jacobs $\mathrm{S}$ et al. Identifying and managing performance concerns in UK community pharmacists. J Health Serv Res Policy. 2013; 18:144-150

63. Hassell K et al. Managing performance concerns about pharmacists: A report for the National Clinical Assessment Service. London, UK: National Clinical Assessment, 2010. 


\begin{tabular}{|c|c|c|c|c|c|c|}
\hline $\begin{array}{l}\text { ID } \\
\text { number }\end{array}$ & Sector & Employed in & Employer code & Role & $\begin{array}{l}\text { Background of } \\
\text { the interviewee }\end{array}$ & $\begin{array}{l}\text { Location of } \\
\text { interviewee }\end{array}$ \\
\hline E1 & Hospital & Children's NHS Trust & Hospital one & $\begin{array}{l}\text { Chair of Safety } \\
\text { Medication Practice }\end{array}$ & Pharmacist & $\begin{array}{l}\text { North West of } \\
\text { England }\end{array}$ \\
\hline E3 & Hospital & Mental Health Trust & Hospital two & $\begin{array}{l}\text { Training and Education } \\
\text { Pharmacist }\end{array}$ & Pharmacist & $\begin{array}{l}\text { North West of } \\
\text { England }\end{array}$ \\
\hline E6 & Community & Medium chain & Company one & $\begin{array}{l}\text { Business Development } \\
\text { Manager }\end{array}$ & Pharmacist & Head office \\
\hline E5 & Community & Supermarket chain & Company two & $\begin{array}{l}\text { Pharmacy Training } \\
\text { Officer }\end{array}$ & Pharmacist & Head office \\
\hline E8 & Community & National chain & Company three & UK Resourcing Officer & Non-pharmacist & Head office \\
\hline E9 & Community & Medium chain & Company one & Operation Manager & Pharmacist & Head office \\
\hline E7 & Community & National chain & Company four & Area Pharmacy Manager & Pharmacist & $\begin{array}{l}\text { North West of } \\
\text { England }\end{array}$ \\
\hline E2 & Community & National chain & Company three & Area Pharmacy Manager & Non-pharmacist & $\begin{array}{l}\text { North West of } \\
\text { England }\end{array}$ \\
\hline $\mathrm{E} 4$ & Community & National chain & Company three & Cluster Manager & Non-pharmacist & $\begin{array}{l}\text { North West of } \\
\text { England }\end{array}$ \\
\hline
\end{tabular}

Table 1 - Profile of the interviewed employers 